\title{
Mass Spectrometry Study of Non-Covalent Complexes of Bioflavonoids with Cyclotriveratrylene Synthesized in Subcritical Water
}

\author{
Anna V. Lekar' ${ }^{1}$, Sergey N. Borisenko², Elena V. Vetrova ${ }^{2}$, \\ Roman N. Borisenko ${ }^{2}$, Nickolay I. Borisenko ${ }^{1}$ \\ ${ }^{1}$ Ecological Analytical Center of Southern Federal University, Rostov-on-Don, Russia \\ ${ }^{2}$ Institute of Physical and Organic Chemistry, Southern Federal University, Rostov-on-Don, Russia \\ Email: boni@ipoc.rsu.ru
}

Received January 25, 2013; revised February 26, 2013; accepted March 15, 2013

Copyright (C) 2013 Anna V. Lekar et al. This is an open access article distributed under the Creative Commons Attribution License, which permits unrestricted use, distribution, and reproduction in any medium, provided the original work is properly cited.

\begin{abstract}
Mass spectrometry was used for studying of non-covalent complexes of bioflavonoids with cyclotriveratrylene (CVT). The complexes of cyclotriveratrylene (CVT) with the bioflavonoids (quercetin or dihydroquercetin) have been synthesized in subcritical water. The complexe formation was carried out at different temperatures of subcritical water (from $120^{\circ} \mathrm{C}$ to $230^{\circ} \mathrm{C}$ ). The structure of the inclusion compounds was confirmed by the data of ESI MS spectroscopy. The mass spectrometry results showed the presence of mixed adducts of CTV monomer, dimer, trimer and tetramer with quercetin and dihydroquercetin. Composition of the CTV complexes with the bioflavonoids, which were obtained in subcritical water medium and by traditional method, was compared.
\end{abstract}

Keywords: Subcritical Water; Cyclotriveratrylene (CTV); Quercetin; Dihydroquercetin; ESI Mass Spectrometry

\section{Introduction}

Sub- and super-critical water is gaining increasing attention as it is not only an environmentally friendly solvent but also an attractive reaction medium for a variety of applications. Water has received a great deal of attention as a reaction medium because it is safe, non-toxic, readily available, inexpensive, and environmentally benign. One of the approaches being used in implementing green chemistry practices is to use water as a solvent and reaction medium where it is possible. Its distinctly different behavior compared to water at ambient conditions is due to the dramatic changes in physical properties, namely dielectric strength and ionic product, which in turn can easily be altered by changing temperature and pressure $[1,2]$. Moreover, the properties of a supercritical fluid can be adjusted by manipulating temperature and pressure, so the opportunity exists to fine tune the fluid properties without altering the chemical composition of the solvent [3]. This means that sub- and super-critical water is an "adjustable" solvent (or "turning solvent") of different applications.

In this research, for the first time we used subcritical water as a medium for formation cyclotriveratrylene
(CTV) host-guest complex with biflavonoids (quercetin (Q) and dhydroquercetin (dQ)). Structural formulas of mentioned compounds are shown on in Figure 1. Cyclotriveratrylene (CTV) is rather flexible "host" having the form of a bowl or a shallow saucer [4]. It is capable to bind neutral molecules and even anions, both in a solution and in a solid state. It's known that CTV formed inclusion (host-guest, clathrate) compounds [5] in which molecules of a one compound (the guest) are enclosed in an intramolecular (monomolecular inclusion) or intermolecular (lattice type inclusion) space of the CTV molecules (the host) with no covalent bonds between the two compounds [6]. Obtaining of CTV intramolecular complexes with ordinary solvent molecules is of great scientific and practical interest and important for CTV host-guest chemistry. Formation of inclusion (host-guest) compounds CTV with quercetin and dihydroquercetin was studied at different properties of solvent and reaction medium by varying temperatures of subcritical water medium. Cyclotriveratrylene (CTV) has a relatively rigid bowl-shape and shows quite different host-guest chemistry [7]. In CTV clathrates, guest molecules are usually located out of the host cavity, i.e., it turns out that all CTV crystalline supramolecular associates are exocyclic 


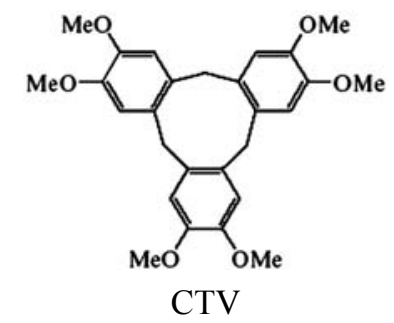

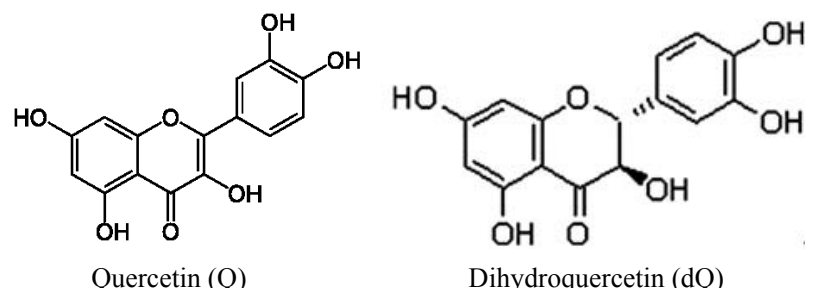

Figure 1. Structural formulas of cyclotriveratrylene, quercetin and dihydroquercetin.

complexes. Intracavity type complexes have been recently obtained for unusual guest molecules such as neutral fullerenes, carboranes and charged organometallic sandwich complexes [5]. Electrospray ionisation mass spectrometry was used for identifycation of non-covalent complexes. In present work, we have used mass spectrometry with electrospray ionization (ESI-MS) techniques to investigate guest-host compositions [8-10] in CTV complexes in samples processed with subcritical water at different temperatures. The existence of a guesthost complex can be confirmed by the presence of the peak of the host-guest complex in mass spectrum.

\section{Material and Methods}

\subsection{Reagents}

Dihydroquercetin obtained from NPF "Flavit" (Russia) and quercetin produced from acid hydrolysis of the rutin standard (from "Merk") were used. Details of cyclotriveratrylene production have been described elsewhere [11].

\subsection{Samples Preparations}

A mixture of $31.5 \mathrm{mg} \mathrm{ml}(1 \mathrm{~mol})$ of CTV, $15 \mathrm{mg}(0.5$ mol) of quercetin (or $15.2 \mathrm{mg}$ dihydroquercetin), and 7 $\mathrm{ml}$ of distilled water was heated for $1 \mathrm{~h}$ in a sealed reactor from stainless steel $(V=10 \mathrm{ml})$. Samples were processed with temperature $120^{\circ} \mathrm{C}, 150^{\circ} \mathrm{C}, 190^{\circ} \mathrm{C}, 230^{\circ} \mathrm{C}$; then evaporated and $1 \mathrm{mg}$ of the solid product was dissolved in acetonitril for mass spectrum studies. Also we prepared samples by traditional method: the inclusion compounds were obtained in result grinding CTV and quercetin in solid state (in ratio 2:1) at room temperature.

\subsection{ESI MS Analysis}

The reaction products were identified and their molecular masses were determined by ESI-MS method using mass spectrometer MS Bruker Daltonic MicrOTOF_Q. In MS studies, all samples were dissolved in acetonitrile ("Merk") at the concentration of $0.5 \mathrm{mg} \cdot \mathrm{ml}^{-1}$. Mass spectra were obtained in positive ion mode in the range of 50 $3000 \mathrm{Da}$, applying identical conditions of the ionization and the detection. The sample was introduced in mass spectrometer directly with the speed of $0.05 \mathrm{mkl} \cdot \mathrm{s}^{-1}$. The effectiveness complexes formation of in different samples was estimated by the comparison of the peaks intensities in mass spectra for the host-guest inclusion compound.

\section{Results}

\subsection{Self-Coupling of Guest-Free CTV}

At the first stage of the research, the guest-free CTV was processed with subcritical water medium and studied as a reference for inclusion complexes. While using mass spectrometry with electrospray ionization (ESI-MS) for analyses of compounds obtained in subcritical water, it was shown that the positively charged ions with similar $\mathrm{m} / \mathrm{z}$ values are present in all studied samples. The relative intensities of these peaks for the samples processed with subcritical water medium and standard solution (control) of guest-free CTV are shown on Figure 2.

In mass spectra the peaks corresponding to mixed adducts of dimer, trimer with $\mathrm{m} / \mathrm{z} 923.39$ и 939.37 ([2 $\mathrm{M}^{\text {СТV }}$ $+\mathrm{Na}]^{+}$and $\left[2 \mathrm{M}^{\mathrm{CTV}}+\mathrm{K}\right]^{+}$ions), $\mathrm{m} / \mathrm{z} 1373.60$ and 1389.58 $\left(\left[3 \mathrm{M}^{\mathrm{CTV}}+\mathrm{Na}\right]^{+}\right.$and $\left[3 \mathrm{M}^{\mathrm{CTV}}+\mathrm{K}\right]^{+}$ions $)$were recorded. Moreover, in some samples, processed at temperatures $150^{\circ} \mathrm{C}, 190^{\circ} \mathrm{C}$ and $230^{\circ} \mathrm{C}$ the low intensity peaks $\mathrm{m} / \mathrm{z}$ 1823.80 for the $\left[4 \mathrm{M}^{\mathrm{CTV}}+\mathrm{Na}\right]^{+}$ion of CTV tetramer were identified. The $m / z 473.19$ and 489.16 for $\left[\mathrm{M}^{\mathrm{CTV}}+\mathrm{Na}\right]^{+}$ and $\left[\mathrm{M}^{\mathrm{CTV}}+\mathrm{K}\right]^{+}$ions were observed in mass spectra also. Only single charged ions were detected. The fractions of the compounds in the mixture were determined by the method of internal normalization.

According to the peaks intensities, the main ion ob-

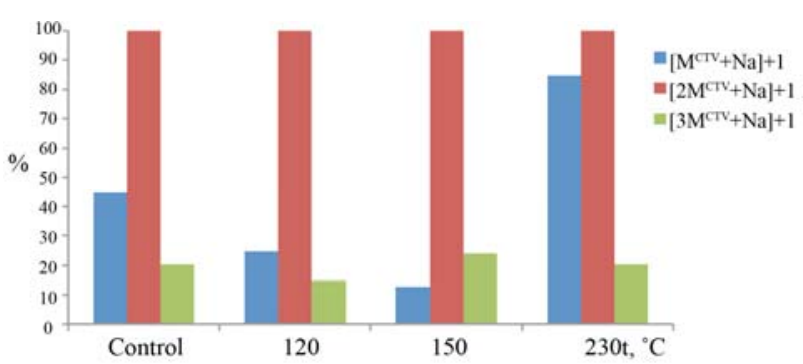

Figure 2. Relative intensities of the peaks in mass spectra for samples, which was processed with subcritical water at different temperature: $\mathrm{m} / \mathrm{z} \mathbf{4 7 3 . 1 9}$ for the $\left[\mathrm{M}^{\mathrm{CTV}}+\mathrm{Na}^{+}\right.$ion (the CTV monomer); $m / z 923.39$ for the $\left[2 \mathrm{M}^{\mathrm{CTV}}+\mathrm{Na}\right]^{+}$ion (CTV dimer); $m / z 1373.60$ for the $\left[3 \mathrm{M}^{\mathrm{CTV}}+\mathrm{Na}\right]^{+}$ion (CTV trimer). 
served in mass spectra for guest-free CTV in all studied samples was $m / z 1373.60$ for the $\left[2 \mathrm{M}^{\mathrm{CTV}}+\mathrm{Na}\right]^{+}$ion (CTV dimer with sodium). The mass spectra of the guestfree CTV, which were processed with subcritical water and the standard solution are similar, which means that subcritical water medium dose not influence on self-coupling CTV. Only in the sample processed with subcritical water at $230^{\circ} \mathrm{C}$ the peak intensity for $\left[\mathrm{M}^{\mathrm{CTV}}+\mathrm{Na}\right]^{+}$ions was larger then that in other samples. Probably efficiency of CTV dimmers destruction while heating is increasing.

\subsection{Inclusion Compounds CTV with Quercetin in Subcritical Water Medium.}

When quercetin was added to the CTV, the peaks for inclusion compounds CTV with quercetin were observed in the mass spectra in positive mode. We found the peaks corresponding to complexes of different compositions. The CTV monomer, dimer or tetramer with inclusion of one or three molecules of quercetin was detected. Figure 3 shows relative intensities of the peaks for the ions consist of CTV and quercetin molecules, for samples processed with subcritical water at different temperatures and

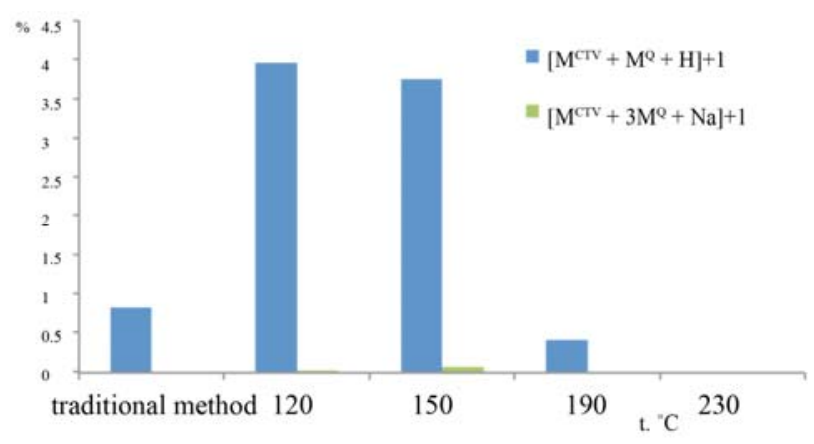

(a)

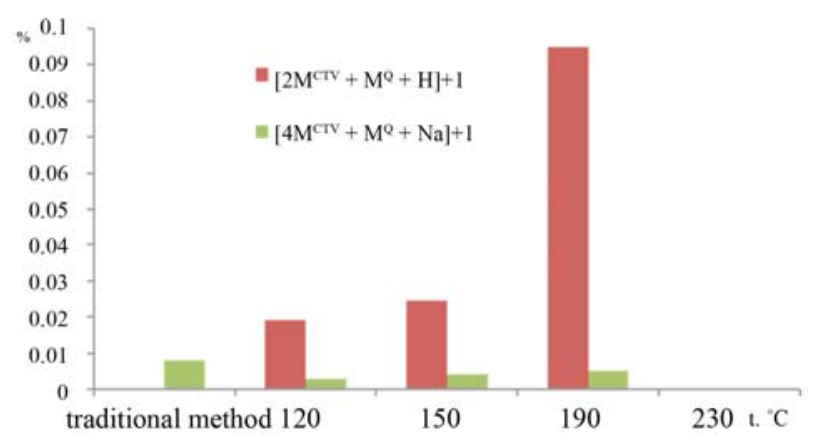

(b)

Figure 3. Relative intensities of the peaks in the mass spectra for samples, which was processed with subcritical water at different temperature: a) inclusion complexes of monomer CTV with quercetin: $m / z 753.23$ for the $\left[M^{\mathrm{CTV}}+\mathbf{M}^{\mathrm{Q}}+\right.$ $\mathrm{H}]^{+}$ion, $m / z 1357,46$ for the $\left[\mathrm{M}^{\mathrm{CTV}}+3 \mathrm{M}^{\mathrm{Q}}+\mathrm{Na}\right]^{+}$ion, $\left.\mathrm{b}\right)$ inclusion complexes of di- and tetramer $\mathrm{CTV}$ with quercetin: $m / z 1203,42$ for the $\left[2 M^{\mathrm{CTV}}+\mathrm{M}^{\mathrm{Q}}+\mathrm{H}\right]^{+}$ion, $m / z$ 2125.90, for $\left[4 \mathrm{M}^{\mathrm{CTV}}+\mathrm{M}^{\mathrm{Q}}+\mathrm{Na}\right]^{+}$ion. the sample obtained in result of grinding CTV and quercetin in solid state. The peak $m / z 753.23$ for the $\left[\mathrm{M}^{\mathrm{CTV}}+\right.$ $\left.\mathrm{M}^{\mathrm{Q}}+\mathrm{H}\right]^{+}$ion was present in the samples, which were obtained in subcritical water at temperatures from $120^{\circ} \mathrm{C}$ to $190^{\circ} \mathrm{C}$. Most intensive peaks for $\left[\mathrm{M}^{\mathrm{CTV}}+\mathrm{M}^{\mathrm{Q}}+\mathrm{H}\right]^{+}$ion were recorded in samples obtained at $120^{\circ} \mathrm{C}$ and $150^{\circ} \mathrm{C}$, but this peak was not observed in mass spectra of samples formed at $230^{\circ} \mathrm{C}$. In all samples produced at $120^{\circ} \mathrm{C}$ and $150^{\circ} \mathrm{C}$, we found the complex with $\mathrm{m} / \mathrm{z} 1357.46$ for the $\left[\mathrm{M}^{\mathrm{CTV}}+3 \mathrm{M}^{\mathrm{Q}}+\mathrm{Na}\right]^{+}$ion but its peak intensity did not exceeded $0.1 \%$. It should be noted that simultaneously with increase of CTV plus quercetin complexes peaks intensity the intensity the molecular ion of quercetin peak with $\mathrm{m} / \mathrm{z} 303.04$ was decreased. It shows the inclusion of quercetin molecules in a complex with CTV. Complexes with dimer of CTV and quercetin molecules were found as $\left[2 \mathrm{M}^{\mathrm{CTV}}+\mathrm{M}^{\mathrm{Q}}+\mathrm{H}\right]^{+}$ion with $m / z$ 1203.42. In spite of dimer of guest-free CTV in control samples were prevailed over other adducts; the relative intensities of peaks for complexes CTV dimmers with quercetin molecules in mass spectra were much smaller than those of complexes CTV-quercetin in ratio of 1:1. Although no one samples did not contain the complexes with trimer CTV, we identified low-intensity peaks $m / z 2125.90$, for $\left[4 \mathrm{M}^{\mathrm{CTV}}+\mathrm{M}^{\mathrm{Q}}\right.$ $+\mathrm{Na}]^{+}$ion, which consisted of CTV tetramer, one molecule of quercetin and potassium and whose intensity did not exceed $0.01 \%$. No comlexation of CTV-quercetin was identified in the samples processed with subcritical water at $230^{\circ} \mathrm{C}$. So, formation of no covalent interaction between CTV and quercetin was more effective at temperature from $120^{\circ} \mathrm{C}$ to $190^{\circ} \mathrm{C}$.

Also, we studied the samples of complex prepared by traditional method by grinding CTV and quercetin in solid state. The mass spectra of this samples shown the peaks $m / z 753.23$ for the $\left[\mathrm{M}^{\mathrm{CTV}}+\mathrm{M}^{\mathrm{Q}}+\mathrm{H}\right]^{+}$ion, $m / z$ 1203.42 for the $\left[2 \mathrm{M}^{\mathrm{CTV}}+\mathrm{M}^{\mathrm{Q}}+\mathrm{H}\right]^{+}$ion and $\mathrm{m} / \mathrm{z} 2125.90$, for $\left[4 \mathrm{M}^{\mathrm{CTV}}+\mathrm{M}^{\mathrm{Q}}+\mathrm{Na}\right]^{+}$ion, but intensities of the peaks in mass spectra were much smaller then that for samples obtained in subcritical water medium at temperature from $120^{\circ} \mathrm{C}$ to $190^{\circ} \mathrm{C}$. Thus, as a result of mass-spectrometric studies have shown that mono-, di- and tetramers CTV form inclusion complexes with 1 molecule of quercetin. Inclusion of 3 molecules of quercetin was observed only in the case of CTV monomer (peak intensity did not exceed $0.25 \%$ ). Participation of CTV monomers in formation of complexes takes place most efficiently for samples processed with subcritical water at temperature of $120^{\circ} \mathrm{C}-150^{\circ} \mathrm{C}$.

\subsection{Inclusion Compounds CTV with Dihydroquercetin in Subcritical Water Medium}

Formation of complexes adducts of mono-, di-, tri- and tetramers CTV with only one molecule of dihydroquer- 
cetin were identified in the samples processed in subcritical water medium. Figure 4 shows relative intensities of the peaks for the ions consist of CTV and dihydroquercetin molecules, for samples processed with subcritical water at different temperatures and the sample obtained in result of grinding CTV and dihydroquercetin in solid state. Highest intensity among the inclusion compounds belongs to $\left[\mathrm{M}^{\mathrm{CTV}}+\mathrm{M}^{\mathrm{dQ}}+\mathrm{H}\right]^{+}$ion, which intensity reached $57 \%$ in the samples processed with subcritical water at $120^{\circ} \mathrm{C}$. In this samples, the dimer CTV with one molecule of dihydroquercetin were also seen, but their peak intensity was not exceed $0.33 \%$. In other samples, we observed the peak $\mathrm{m} / \mathrm{z} 777.1652$ for the $\left[\mathrm{M}^{\mathrm{CTV}}+\mathrm{M}^{\mathrm{dQ}}+\mathrm{Na}\right]^{+}$ion. Intensity of this peak was increased as temperature of subcritical water growing up and reached $7.5 \%$ at $230^{\circ} \mathrm{C}$. The mass spectra shown the peak with dimer of CTV m/z 1227.32 for the $\left[2 \mathrm{M}^{\mathrm{CTV}}+\right.$ $\left.\mathrm{M}^{\mathrm{dQ}}+\mathrm{Na}\right]^{+}$ion. Intensity of the peak was less then $3 \%$. Low-intensity peak $m / z 1677.48$ for the $\left[3 \mathrm{M}^{\mathrm{CTV}}+\mathrm{M}^{\mathrm{dQ}}+\right.$ $\mathrm{Na}]^{+}$ion was observed in some samples and peak intensity did not exceed $0.23 \%$. Complex with CTV tetramer was identified in samples at temperature $150^{\circ} \mathrm{C}-190^{\circ} \mathrm{C}$, intensity of the peak $\mathrm{m} / \mathrm{z} 2126.67$ for $\left[4 \mathrm{M}^{\mathrm{CTV}}+\mathrm{M}^{\mathrm{dQ}}+\right.$

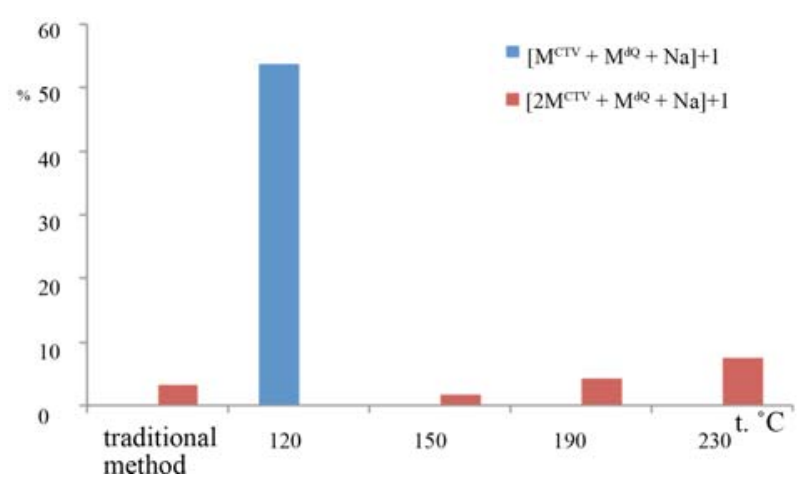

(a)

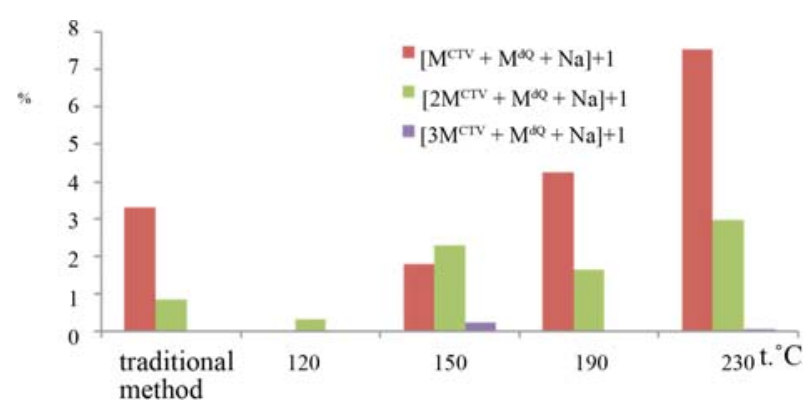

(b)

Figure 4. Relative intensities of the peaks in the mass spectra for samples, which was processed with subcritical water at different temperature: a) inclusion complexes of monomer CTV with dihydroquercetin: $m / z$ 755,08 for the [M ${ }^{\text {CTV }}$ $+\mathrm{M}^{\mathrm{dQ}}+\mathrm{H}^{+}$ion, $m / \mathbf{z} 777.16$ for the $\left[\mathrm{M}^{\mathrm{CTV}}+\mathrm{M}^{\mathrm{dQ}}+\mathrm{Na}\right]^{+}$ion, b) inclusion complexes of di- and trimer CTV with quercetin: $m / z 1227.32$ for the $\left[2 \mathrm{M}^{\mathrm{CTV}}+\mathrm{M}^{\mathrm{dQ}}+\mathrm{Na}\right]^{+}$ion, $m / z$ 1677.48 for the $\left[3 M^{\mathrm{CTV}}+\mathrm{M}^{\mathrm{dQ}}+\mathrm{Na}\right]^{+}$ion.
$\mathrm{Na}]^{+}$ions was $0.02 \%$.

Samples were prepared using the traditional method by grinding CTV and quercetin in solid state. The mass spectra of this samples shown only two peaks for the complexes with CTV monomer and dimer as the $\left[\mathrm{M}^{\mathrm{CTV}}+\right.$ $\left.\mathrm{M}^{\mathrm{dQ}}+\mathrm{Na}\right]^{+}$and $\left[2 \mathrm{M}^{\mathrm{CTV}}+\mathrm{M}^{\mathrm{dQ}}+\mathrm{Na}\right]^{+}$ions respectively. Intensities of the peaks in mass spectra were smaller then that for samples obtained in subcritical water medium at temperature $120^{\circ} \mathrm{C}, 190^{\circ} \mathrm{C}$ and $230^{\circ} \mathrm{C}$.

Thus, as a result of mass-spectrometric studies have shown that mono-, di-, tri- and tetramers CTV form inclusion complexes with one molecule of dihydroquercetin. With CTV monomers formation of complexes takes place efficiently and the most efficient for samples processed with subcritical water at temperature of $120^{\circ} \mathrm{C}$ $150^{\circ} \mathrm{C}$. At the average the peaks intensities for complexes CTV with dihydroquercetin were higher then for complexes with quercetin. CTV includes dihydroquercetin more effectively then quercetin.

\section{Conclusion}

In present research, for the first time subcritical water medium was used to form the inclusion compound CTV with a bioflavonoids. It is shown that, in the subcritical water medium, formation of complexes CTV with quercetin or dihydroquercetin is more effective than using traditional methods. The structure of complexes cyclotriveratrylene with quercetin and dihydroquercetin obtained in subcritical water is confirmed by the data of ESI MS spectroscopy. Moreover, the mass spectrometry results showed the presence of mixed adducts of CTV monomer, dimer, trimer and tetramer type. Mass spectrometry with ES ionization successfully used to the identification of non-covalent complexes of CTV with bioflavonoids was obtained under conditions of subcritical water. Despite the fact that the methods of solution phase are still required to fully understand the mode of binding, ESI-MS has advantages in speed, stoichiometry and sensitivity analysis of non-covalent interactions, including in terms of primary screening of the reaction products. ESI MS method sensitivity is sufficient to capture the formation of small quantities of complex compounds and to select optimal conditions for obtaining products of a given composition. All products of interaction CTV with a bioflavonoid in the subcritical water medium should be studied in more detail.

\section{Acknowledgements}

This work was supported by the government task for the universities, project No. 3.5193.2011, Grant of the President aimed on support for leading scientific school 927.2012.3, Federal target program Scientific and pedagogical personnel of innovative Russia" (government 
contract No. 16.740.11.0600) and RFBR projects 13-0312271, 13-03-01318.

\section{REFERENCES}

[1] A. Kruse and E. Dinjus, "Hot Compressed Water as Reaction Medium and Reactant Properties and Synthesis Reactions," The Journal of Supercritical Fluids, Vol. 39, No. 3, 2007, pp. 362-380.

[2] P. E. Savage, "A Perspective on Catalysis in Sub- and Supercritical Water," The Journal of Supercritical Fluids, Vol. 47, No. 3, 2009, pp. 407-414. doi:10.1016/j.supflu.2008.09.007

[3] C. Eckert and K. Chandler, "Tuning Fluid Solvents for Chemical Reactions," The Journal of Supercritical Fluids, Vol. 13, No. 1-3, 1998, pp. 187-195. doi:10.1016/S0896-8446(98)00051-5

[4] N. E. Burlinson and J. A. Ripmeester, "Characterization of Cyclotriveratrylene Inclusion Compounds by Means of Solid State 13C NMR," Journal of inclusion Phenomena, Vol. 1, No. 4, 1984, pp. 403-409.

[5] J. W. Steed and J. L. Atwood, "Supramolecular Chemistry," John Wiley \& Sons Ltd, West Sussex, 2000.

[6] J.-M. Lehn, "Supramolecular Chemistry: Concepts and Perspectives," VCH, Weinheim, 1995.

doi:10.1002/3527607439
[7] H. Zhang nad J. L. Atwood, "Crystal and Molecular Structure of Cyclotriveratrylene," Journal of Crystallographic and Spectroscopic Research, Vol. 20, No. 5, 1990, pp. 465-470.

[8] J. M. Daniel, S. D. Friess, S. Rajagopalan, S. Wendt and R. Zenobi, "Quantitative Determination of Noncovalent Binding Interactions Using Soft Ionization Mass Spectrometry," International Journal of Mass Spectrometry, Vol. 216, No. 1, 2002, pp. 1-27. doi:10.1016/S1387-3806(02)00585-7

[9] P. A. Brady and J. K. M. Sanders, "Electrospray Mass Spectrometry and Supramolecular Complexes: Quantifying the Metal Ion Binding Properties of Cholic Acid Derivatives," New Journal of Chemistry, Vol. 22, No. 5, 1998, pp. 411-417. doi:10.1039/a800524i

[10] C. Wana, M. Cuia, F. Songa, Z Liua and S. Liua, "A Study of the Non-Covalent Interaction between Flavonoids and DNA Triplexes by Electrospray Ionization Mass Spectrometry," International Journal of Mass Spectrometry, Vol. 283, No. 1-3, 2009, pp. 48-55. doi:10.1016/j.ijms.2009.01.007

[11] S. N. Borisenko, M. I. Rudnev, A. V. Bicherov, O. V. Ryabtsova, N. I. Borisenko, E. V. Vetrova, V. I. Minkin and A. V. Lekar, "Products of the Interaction of Veratrole and Paraform in a Subcritical Water Medium," Russian Journal of Physical Chemistry B, Vol. 3, No. 7, 2009, pp. 100-103. 